\title{
Risky robbing is a job for short-lived and infected worker honeybees
}

\author{
Karolina KuszewsKa, Michal WoycIECHOwsKI \\ Institute of Environmental Sciences, Jagiellonian University, Gronostajowa 7, 30-387, Krakow, Poland
}

Received 7 August 2013 - Revised 8 November 2013 - Accepted 2 January 2014

\begin{abstract}
Researchers in many fields would like to understand the determinants of risk-taking. Social insects are an excellent model for examining them since the tasks they perform bear different risks. Some honeybee (Apis mellifera) workers do not forage for nectar or pollen; instead, they take on the extreme risk of robbing honey from other bee nests. In this paper, we show that robbers live shorter lives than foragers under the same cage conditions, and that they are more often and more heavily infected with the intestinal parasite Nosema than foragers are. This finding supports the theoretical prediction that risky tasks should be undertaken by shorter-lived individuals.
\end{abstract}

Apis mellifera / division of labour by division of risk / life expectancy / robber bees / Nosema

\section{INTRODUCTION}

The factors that affect risk-taking are addressed in many fields of study. Economists and psychologists focus on revealing the mechanisms of risktaking and the consequences of those choices (Sanfey et al. 2003; Paulus 2007; Lawrence et al. 2008). Evolutionary biologists want to understand how animals maximize their fitness by undertaking risks related to different benefits (Kacelnik and Bateson 1997). Social insects give us an excellent model for analysing risk-taking, since the individual workers' decision depends on the behaviour of other group members, affects the productivity of the colony, and thus can benefit or harm the inclusive fitness of all colony members. Most insect communities have an age-related division of labour: younger adult workers execute safe tasks inside the nest; later in life they

Corresponding author: K. Kuszewska,

k.kuszewska@uj.edu.pl

Manuscript editor: David Tarpy undertake riskier outside-nest tasks like foraging (Winston 1987; Schmid-Hempel and SchmidHempel 1984; Visscher and Dukas 1997). Risktaking by social insects is not limited to a choice between inside- or outside-nest tasks. Tasks performed by workers outside the nest can also differ in the risk level. Ant (Cataglyphis sp.) foragers are safer at optimal temperature than under thermal stress (Cedrá and Retana 2000; Clémencet et al. 2010). Among honeybee (Apis mellifera) foragers, collecting water is more risky than collecting nectar (Woyciechowski 2007), and foraging is riskier during inclement weather than during fair weather (Woyciechowski and Kozlowski 1998). Robbing the provisions stored in foreign bee nests is a task associated with extremely high risk. Individuals undertaking robbery are vulnerable to direct attack by nest defenders and can have their wings damaged or they can even be killed during their mission (Free 1954; Winston 1987).

Many proximate factors influence workers' movement from inside-nest task to outside-nest foraging. It is well-known that the time for 
onset of foraging is related to the genotype of the workers (Page et al. 2000), the hormone titre in hemolymph (Pankiw 2004), colony demography (Robinson 1992), and environmental components (Robinson 1992; Gordon 1996). Considerably seldom discussed, however, are the ultimate factors in the evolution of the division of labour based on age polyethism. Jeanne (1986) and Tofilski (2002) explored the evolutionary factors of age polyethism. They showed that executing risky tasks later in the workers' life can prolong their mean longevity. Such a choice increases the colony's reproductive success (Schmid-Hempel and Wolf 1988). Based on similar assumptions, the 'division of labour by division of risk' hypothesis (Woyciechowski and Kozłowski 1998) suggests that the decision as to which individual undertakes a certain task in a colony arises from the division of risk among workers differing in their life expectancy: individuals with a longer life expectancy, which is to say the young and/or healthy, should undertake less risky tasks than should workers with a shorter life expectancy, namely those older and/or infected with pathogens.

There are experimental results that show a relationship between the life expectancy of workers and the onset of their foraging. As predicted, workers with a longer life expectancy initiated risky foraging later in life than did sameage workers whose life expectancy was experimentally shortened. This has been observed in the ant, Myrmica scabrinodis (Moroń et al. 2008), and the honeybee (Woyciechowski and Moroń 2009). The converse was confirmed in a study of behavioural reversion in honeybee colonies: foragers with experimentally shortened life expectancy reverted to a safe inside-nest task less frequently than did same-age foragers from the control groups (Kuszewska and Woyciechowski 2013). In another recent study, M. scabrinodis foragers with experimentally shortened life expectancy undertook foraging under higher risk (farther from the nest; higher temperature; presence of competitors) than those from the control group (Moroń et al. 2012).

In all of those cited studies testing the 'division of labour by division of risk' hypothesis, the life expectancy of individuals was artificially manipulated. Little is known about whether risk-taking depends directly on worker life expectancy in natural field conditions. Here, we compared the life expectancy and levels of infection with the intestinal parasite Nosema sp. between honeybee workers performing outside-nest tasks associated with different risks - foraging for nectar and pollen (lower risk) and robbing the provisions stored in foreign bee nests (higher risk). We expected the robbers to have a shorter lifespan and to be infected more frequently and with a larger number of spores than the bees foraging for nectar and pollen.

\section{METHODS}

The study, conducted from 4 to 18 September, used 16 colonies of honeybees (A. m. carnica) in the experimental apiary of the Institute of Environmental Sciences (Krakow, southern Poland). All colonies were regularly inspected and never showed symptoms of Nosema infection. The experiment was done during a period when robbing is often observed. Foragers and robbers were collected in the early afternoon. Bees that collected nectar or pollen from flowers no more than $50 \mathrm{~m}$ from the apiary were considered foragers; workers that performed characteristic swaying flight (Free 1954) and tried to get into hives by means other than through the entrance (Muszyńska 1993) were considered robbers.

The two groups of captured bees, robbers and foragers, were marked with different colours and caged in order to assess their lifespan independently of external mortality. These bees were randomly placed in four cages $(15 \times 14 \times 6 \mathrm{~cm}$, wood-framed, with glass in one side and steel mesh in the other side) and provided with a small piece of bee comb. There were 27-33 workers per group (robbers and foragers) in each of the four test cages. The cages were incubated at $36{ }^{\circ} \mathrm{C}$ and $60 \% \mathrm{RH}$ and provided with sucrose syrup $(50 \% \mathrm{w} / \mathrm{v}$, ad libitum). The cages were checked every day, and dead bees were counted and removed.

Separately, foraging bees (60 workers) and robbers (70 workers) were collected, frozen immediately, and then dissected in order to detect and count Nosema sp. spores in their intestines. To do this, the digestive tract 
(without crop) of each bee was homogenised in $300 \mu \mathrm{L}$ distilled water. The Nosema spores were counted in a Bürker haemocytometer in a total solution volume of $1.25 \times 10^{-2} \mu \mathrm{L}$. If the number of spores counted per sample was less than 10 , the total solution volume per sample was increased to $8 \times 10^{-2} \mu \mathrm{L}$. The total number of spores per bee was determined according to the following formula: number of spores per bee $=$ number of spores per sample $\times 300 \mu \mathrm{L} /$ total solution volume of sample.

The difference in survival between robbers and foraging workers was analysed using a generalized linear/nonlinear model (GLZ) module in Statistica 9.0 (StatSoft 2012) with Poisson distribution and the Link function of LOG, which is a semiparametric statistical test (Härdle et al. 1996). Cage was a random effect, and group (robbers or foragers) was a fixed effect. If the effect of a factor was statistically significant, GLZ was followed by multiple comparisons using the post-hoc Tukey HSD test with 0.05 taken as indicating significance. The proportions of infected and uninfected workers was compared between foragers and robbers using the G-test with William's correction, and the significance of differences in levels of infection between foragers and robbers was tested using the nonparametric MannWhitney $U$ test. All calculations were conducted with two-tailed statistical test and were performed with STATISTICA 9.0.

\section{RESULTS}

In our laboratory experiment with caged workers, the lifespan of the robbers was significantly shorter than that of the nectar or pollen foragers (GLZ, Wald's $\chi^{2}=60.541, P<0.001$; Figure 1). Lifespan was also affected by the cage in which the bees were kept (GLZ, Wald's $\chi^{2}=$ 64.390, $P<0.001$ ); the post-hoc Tukey HSD test showed that this difference in longevity was between the bees kept in cage 3 and the ones in cages 1 and 4 (Tukey HSD, $P<0.05$ ). The interaction between group and cage did not influence the longevity of the robbers or foragers (GLZ, Wald's $\chi^{2}=1.116, P=0.773$ ).

Among the bees collected straight from the field, Nosema spores were more prevalent and

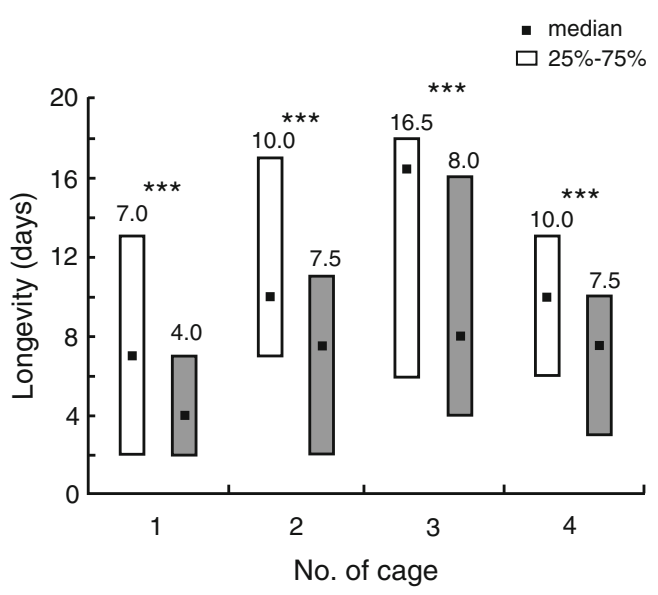

Figure 1. Longevity (median and quartiles) of foragers (empty bars) and robbers (grey bars) in the cage experiment. Numbers indicate the median of longevity (in days) in each group. The stars indicate significant differences $(P<0.001)$ between robbers and foragers in each cage

abundant in robbers than in foragers. Among the 60 nectar- or pollen-foraging workers, 53 (88\%) were infected with Nosema spores; 69 $(98.5 \%)$ of the 70 robbers were infected. The difference in prevalence was significant ( $G$-test: $G=6.323, d f=1, P<0.0120)$. Nosema spores were also more abundant in robber workers $\left(\right.$ median $\left.4.080 \times 10^{5}\right)$ than in foragers (median $\left.0.169 \times 10^{5}\right)$; the difference was significant (Mann-Whitney $U$ test: $U=623, Z=-6.89$, $N_{1}=70 N_{2}=80, P<0.02$; Figure 2).

\section{DISCUSSION}

Here, we demonstrated that workers undertaking to rob nests, a risky task, were shorterlived than nectar and pollen foragers (Figure 1). These results are in line with the expectations of the 'division of labour by division of risk' hypothesis (Woyciechowski and Kozlowski 1998) and strongly suggest that individuals with a shorter life expectancy undertake riskier tasks than do longer-lived workers (Tofilski 2009). In eusocial insects, it is a rule that workers undertake safe inside-nest tasks earlier in life 


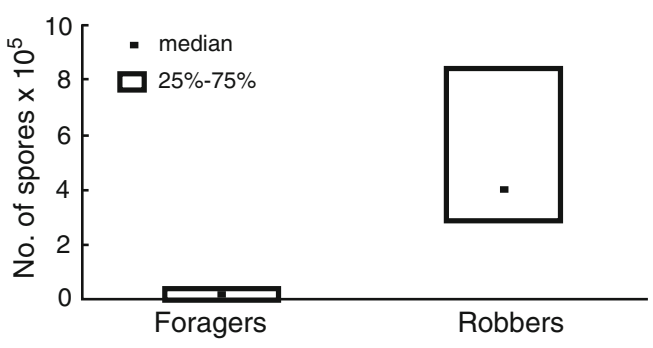

Figure 2. Number of Nosema sp. spores in foraging and robbing workers

than risky foraging, and according to our knowledge, there are only two exceptions from this rule, one found in a species of termite (Zootermopsis angusticollis) and another in a species of ant (Amblyopone pallipes) by Traniello and Rosengaus (1997). There are even examples of task partitioning in which the task consists of two subtasks differing in the associated risk. In the honeybee, nectar is collected by foragers under more dangerous conditions, but is stored in comb cells by inside-nest younger workers in much safer conditions. Another example is from the leaf cutting ant, Atta cephalotes: younger workers remove waste from the fungus garden and transfer it to the garbage chamber, which is staffed by older workers performing the last task of their lives; they never will leave that chamber (Bot et al. 2001). The workers living in the garbage chamber are exposed to potentially pathogenic waste material and usually live only a few days after starting on this job (Hart and Ratnieks 2001). Both of these examples of task partitioning show the association between worker life expectancy and the risk involved in the task undertaken.

Our data demonstrate that honeybee robbers not only lived shorter lives but were infected with Nosema spores more frequently and more heavily than the foragers were (Figure 2). This result doubly confirms our predictions since previous studies have shown that individuals infected with $N$. apis have a shorter lifespan (Woyciechowski and Moron 2009) and more often than healthy foragers collect nectar during unfavourable weather conditions (Woyciechowski and Kozlowski 1998). Higher levels of $N$. apis infection often are associated with worker age (Malone and Giacon 1996). Older workers generally are more heavily infected than younger bees (Smart and Sheppard 2012), a finding attributable to their longer exposure to the parasite (El-Shemy and Pickard 1989) or to the 6-day developmental life cycle of Nosema, relatively long in relation to the workers' lifetime (Fries 1988). Wang and Moeller (1970) even suggested that Nosemainfected workers are physiologically older than the same-age healthy bees and therefore carry out some activities at an earlier age (Woyciechowski and Moron 2009; Goblirsch et al. 2013). This means that regardless of the reason, be it age or disease, the robbers had a shorter life expectancy and had therefore undertaken a task involving a greater risk.

The mortality rate is higher outside the nest than inside, due not only to greater exposure to external hazards (e.g. predators, accidents, disorientation) but also to internal resource depletion (Neukirch 1982, Woyciechowski 2007). Honeybee workers have a limited energy reserve in their flight muscles and when this is used up, they cannot fly and return to the colony. This results in their death (Neukirch 1982; Page and Peng 2001). Rueppell et al. (2007) showed that internal resource depletion has a greater impact on the longevity of bees than external hazards because workers foraging for longer periods had shorter lifespans than those with a limited amount of time for foraging. In our experiment, we compared two groups of free-flying bees performing, respectively, low- or high-risk tasks. We have no reason to suspect that robbers and foragers differed in length of flying time and thus in internal resource depletion.

Our main conclusion does not challenge the idea that the energetic state affects the decision to start foraging by honeybee workers (Mayack and Naug 2011). Nosema imposes an energetic stress on infected bees, which have an elevated appetite and hunger level (Mayack and Naug 2009, 2010). Kaatz at al. (1994) showed that starved workers had higher juvenile hormone 
titres, while Alaux et al. (2010) suggested that the energetic stress associated with malnutrition probably is one of the causes of immunodeficiency in honeybee colonies. Interestingly, old workers are more sensitive than younger bees to starvation stress, which causes increased mortality (Remolina et al. 2007). These examples seem to support the idea that the energetic shortfall is a cause of shorter life expectancy; that would explain why workers are slotted to safer or riskier tasks.

Alternative explanations of our results are possible. One is that robbers potentially are more exposed to Nosema infection than foragers if they rob honey from heavily infected colonies (Fries and Camazine 2001). A high level of infection produces yellow or yellowish brown excrement stains inside the hive. In the colonies where the Nosema infection is mild, if any excrement is laid on the comb, it is quickly removed by resident workers, so the chance of infecting robbers is very low. No colonies in our experimental apiary were so heavily infected during the study (i.e. no excrements were visible on frames) that the parasite would have been transmitted horizontally by robbing workers, so it is reasonable to conclude that the Nosema infection that shortened the life expectancy of our honeybee workers is better explained as a cause rather than a consequence of robbery. We also realise that robbers had already suffered some damage while fighting in the course of robbery, and this could influence their longevity in our cage experiment. It is difficult to distinguish whether longevity determines the type of performed task, or whether the performed task influences longevity. There are many papers showing that both of these explanations are possible and that neither of them excludes the other (Neukirch 1982; Amdam and Omholt 2002; Rueppell et al. 2007). However, according to our observations, robbing workers can be stung and die immediately or can suffer from destruction of their wings, which has no impact on their life expectancy if they are caged. Therefore, we believe that our results show clearly enough that more prevalent and abundant Nosema spores in robber bees were the cause of their higher mortality relative to foraging bees.

An alternative explanation is that the infected workers' tendency to rob may be caused by the parasite manipulating the behaviour of its host and provoking it to visit other colonies. This would be a way of increasing horizontal transmission of Nosema. Parasites have been suggested to affect the behaviour of host social insects. Honeybee workers infected with Nosema ceranae tend to remain in places where the temperature is higher (Campbell et al. 2010), which increases the reproductive potential of the parasite (Martín-Hernández et al. 2009). Workers infested with Varroa destructor or Nosema have a reduced spatial orientation capacity (Kralj and Fuchs 2006; Kralj and Fuchs 2010), which increases the chances of infecting bees from other colonies. As suggested by those authors, however, such a response in infected individuals probably is the result of the overall reaction to the presence of the parasite. If the parasite had indeed manipulated the workers' behaviour in our study, we should have seen robbing being done throughout the season, as well as in the spring when the first increase of infected workers occurs (Mattila and Otis 2006). Robbing is observed almost exclusively later in the summer when resources are not readily available in the field (Free 1954; Winston 1987). It is unlikely that the parasites would manipulate the host's behaviour only during the part of the season when the host's food resources are least. The much more probable explanation is simply that the bees tend to rob when pollen and nectar are in short supply.

Another possible hypothesis is that more heavily infected robber workers have taken the route of altruistic suicide because their presence is harmful to their native colony members. Such behaviour has been observed in ants (Temnothorax unifasciatus) (Heinze and Walter 2010) and has been suggested as an explanation for the experimental results Rueppell and colleagues (2010) obtained in the honeybee. In both of those studies, moribund workers removed themselves, abandoning the nest and 
their social role, leading to complete or almost complete cessation of all active and passive contact with their nestmates. Robbing workers behave in quite a different way: having successfully gained entry to a foreign colony, they ingest a load of honey and return to the native colony, where they then recruit other workers to rob (Winston 1987; Moritz and Neumann 2004). Active contact such as this on the part of robbers with members of both their own and the robbed colony cannot be linked to altruistic suicide but possibly rather to the parasite manipulation discussed above.

Our results are consistent with the prediction that tasks, or more precisely the risks associated with specific tasks, are divided between colony members depending on their life expectancy. One of the riskiest tasks - robbing - is performed by the less valuable members of the colony: the oldest and/or disease-infected. Therefore, it can be supposed that differentiation in worker life expectancy and the different risk related to each task are sufficient factors for the evolution of division of labour in honeybee and probably in all eusocial insects.

\section{ACKNOWLEDGMENTS}

We thank Jan Kozlowski, Adam Lomnicki, Michael Jacobs, Gard W. Otis and two anonymous reviewers for suggestions and comments. This study was funded by the Polish National Science Centre (grant NN 304 059340), the Jagiellonian University (grant DS/BiNoZ/ INoŚ/761/08-13), and the 7th EU FP Collaborative Project STEP (Status and Trends of European Pollinators; 244090, www.STEP-project.net).

\section{OPEN ACCESS}

This article is distributed under the terms of the Creative Commons Attribution License which permits any use, distribution, and reproduction in any medium, provided the original author(s) and the source are credited.

Prendre le risque de voler du miel est une tâche pour les ouvrières à durée de vie courte et fortement infectées par Nosema

Apis mellifera / division du travail / prise de risque / espérance de vie / vol de miel
Riskantes Räuberei ist ein Job für kurzlebige und infizierte Arbeiterinnen

Apis mellifera / Arbeitsteilung / Risikoteilung /

Lebenserwartung / Räuberbienen

\section{REFERENCES}

Alaux, C., Ducloz, F., Crauser, D., Le Conte, Y. (2010) Diet effects on honeybee immunocompetence. Biol. Letters 6(4), 562-565

Amdam, G.V., Omholt, S.W. (2002) The regulatory anatomy of honeybee lifespan. J. Theor. Biol. 216(2), 209-228

Bot, A.M.N., Currie, C.R., Hart, A.G., Boomsma, J.J. (2001) Waste management in leaf-cutting ants. Ethol. Ecol. Evol. 13(3), 225-237

Campbell, J., Kessler, B., Mayack, C., Naug, D. (2010) Behavioural fever in infected honeybees: parasitic manipulation or coincidental benefit? Parasitology 137(10), 1487-1491

Cedrá, X., Retana, J. (2000) Alternative strategies by thermophilic ants to cope with extreme heat: individual versus colony level traits. Oikos 89(1), 155-163

Clémencet, J., Cournault, L., Odent, A., Doums, C. (2010) Worker thermal tolerance in the thermophilic ant Cataglyphis cursor (Hymenoptera, Formicidae). Insectes Soc. 57(1), 11-15

El-Shemy, A.A.M., Pickard, R.S. (1989) Nosema apis Zander infection levels in honeybees of known age. J. Apic. Res. 28(2), 101-106

Free, J.B. (1954) The behaviour of robber honeybees. Behaviour 7, 223-240

Fries, I. (1988) Infectivity and multiplication of Nosema apis Z $\mathrm{Z}$ in the ventriculus of the honey bee. Apidologie 19(3), 319-328

Fries, I., Camazine, S. (2001) Implication of horizontal and vertical pathogen transmission for honey bee epidemiology. Apidologie 32(3), 1-16

Goblirsch, M., Huang, Z.Y., Spivak, M. (2013) Physiological and behavioral changes in honey bees (Apis mellifera) induced by Nosema ceranae infection. PLoS ONE 8(3), e58165. doi:10.1371/journal. pone. 0058165

Gordon, D.M. (1996) The organisation of work in social insects. Nature 380(6570), 121-124

Hart, A.G., Ratnieks, F.L.W. (2001) Task partitioning, division of labour and nest compartmentalization collectively isolate hazardous waste in the leafcutting ant Atta cephalotes. Behav. Ecol. Sociobiol. 49(5), 387-392

Härdle, W., Mammen, E., Müller, M. (1996) Testing parametric versus semiparametric modelling in 
Generalized Linear Models. J. Am. Stat. Assoc. 93(444), 1461-1474

Heinze, J., Walter, B. (2010) Moribund ants leave their nests to die in social isolation. Curr. Biol. 20(3), 249-252

Jeanne, R.L. (1986) The evolution of the organization of work in social insects. Monitore Zool. Ital. (N.S.) 20, 119-133

Kaatz, H., Eichmuller, S., Kreissl, S. (1994) Stimulatory effect of octopamine on juvenile hormone biosynthesis in honey bee (Apis mellifera): physiological and immunocytochemical evidence. J. Insect Physiol. 40(10), 865-872

Kacelnik, A., Bateson, M. (1997) Risk-sensitivity: crossroads for theories of decision-making. Trends Cogn. Sci. 1(8), 304-309

Kralj, J., Fuchs, S. (2006) Parasitic Varroa destructor mites influence flight duration and homing ability of infested Apis mellifera foragers. Apidologie 37(5), 577-587

Kralj, J., Fuchs, S. (2010) Nosema sp. influences flight behavior of infected honeybee (Apis mellifera) foragers. Apidologie 41(1), 21-28

Kuszewska, K., Woyciechowski, M. (2013) Reversion in honeybee, Apis mellifera, workers with different life expectancies. Anim. Behav. 85(1), 247-253

Lawrence, A., Clark, L., Labuzetta, J.N., Sahakian, B., Vyakarnum, S. (2008) The innovative brain. Nature 456(7219), 168-169

Malone, L.M., Giacon, H.A. (1996) Effects of Nosema apis Zander on inbred New Zealand honey bees (Apis mellifera ligustica L.). Apidologie 27(6), 479-486

Martín-Hernández, R., Meana, A., García-Palencia, P., Marín, P., Botías, C., Garrido-Bailón, E., Barrios, L., Higes, M. (2009) Effect of temperature on the biotic potential of honeybee microsporidia. Appl. Environ. Microb. 75(8), 2554-2557

Mattila, H.R., Otis, G.W. (2006) Effects of pollen availability and Nosema infection during the spring on division of labor and survival of worker honey bees (Hymenoptera: Apidae). Environ. Entomol. 35(3), 708-717

Mayack, C., Naug, D. (2009) Energetic stress in the honeybee Apis mellifera from Nosema ceranae infection. J. Invertebr. Pathol. 100(3), 185-188

Mayack, C., Naug, D. (2010) Parasitic infection leads to decline in hemolymph sugar levels in honeybee foragers. J. Insect Physiol. 56(11), 1572-1575

Mayack, C., Naug, D. (2011) A changing but not an absolute energy budget dictates risk-sensitive behaviour in the honeybee. Anim. Behav. 82(3), 595-600

Moritz, R.F.A., Neumann, P. (2004) Differences in nestmate recognition for drones and workers in the honeybee, Apis mellifera (L.). Anim Behav 67(4), 681-688

Moroń, D., Witek, M., Woyciechowski, M. (2008) Division of labour among workers with different life expectancy in the ant Myrmica scabrinodis. Anim. Behav. 75(2), 345-350

Moroń, D., Lenda, M., Skórka, P., Woyciechowski, M. (2012) Short-lived ants take greater risks during food collection. Am. Nat. 180(6), 744-750

Muszyńska, J. (1993) Characterization of robber bees. Pszczeln. Zeszyt. Nauk. 37, 3-9

Neukirch, A. (1982) Dependence of the life span of the honeybee (Apis mellifica) upon flight performance and energy consumption. J. Comp. Physiol. 146(1), 35-40

Page, R.E., Fondrk, M.K., Hunt, G.J., Guzmán-Novoa, E., Humphries, M.A., Nguyen, K., Greene, A.S. (2000) Genetic dissection of honeybee (Apis mellifera L.) foraging behavior. J Hered 91(6), 474-479

Page, R.E., Peng, Y.-S.C. (2001) Aging and development in social insects with emphasis on the honey bee Apis mellifera L. Exp. Gerontol. 36(4), 695-711

Pankiw, T. (2004) Worker honey bee pheromone regulation of foraging ontogeny. Naturwissenschaften 91(4), 178-181

Paulus, M.P. (2007) Decision-making dysfunctions in psychiatry-altered homeostatic processing? Science 318(5850), 602-606

Remolina, S.C., Hafez, D.M., Robinson, G.E., Hughes, K.A. (2007) Senescence in the worker honey bee Apis mellifera. J. Insect Physiol. 52(10), 1027-1033

Robinson, G.E. (1992) Regulation of division of labor in insect societies. Annu. Rev. Entomol. 37(1), 637-665

Rueppell, O., Bachelier, C., Fondrk, M.K., Page Jr., R.E. (2007) Regulation of life history determines lifespan of worker honey bees (Apis mellifera L.). Exp Geront 42(10), 1020-1032

Rueppell, O., Hayworth, M.K., Ross, N.P. (2010) Altruistic self-removal of health-compromised honey bee workers from their hive. J. Evol. Biol. 23(7), 1538-1546

Sanfey, A.G., Rilling, J.K., Aronson, J.A., Nystrom, L.E., Cohen, J.D. (2003) The neural basis of economic decision-making in the Ultimatum Game. Science 300(5626), 1755-1758

Schmid-Hempel, P., Schmid-Hempel, R. (1984) Life duration and turnover of foragers in the ant Cataglyphis bicolor (Hymenoptera, Formicidae). Insectes Soc. 31(4), 345-360

Schmid-Hempel, P., Wolf, T. (1988) Foraging effort and lifespan of workers in a social insect. J. Anim. Ecol. 57, 509-521

Smart, M.D., Sheppard, W.S. (2012) Nosema ceranae in age cohorts of the western honey bee (Apis mellifera). J. Invertebr. Pathol. 109(1), 148-151

Tofilski, A. (2002) Influence of age polyethism on longevity of workers in social insects. Behav. Ecol. Sociobiol. 51(3), 234-237

Tofilski, A. (2009) Shorter-lived workers start foraging earlier. Insect. Soc. 56(4), 359-366 
Traniello, J.F.A., Rosengaus, R.B. (1997) Ecology, evolution and division of labour in social insects. Anim. Behav. 53(1), 209-213

Visscher, P.K., Dukas, R. (1997) Survivorship of foraging honey bees. Insectes Soc. 44(1), 1-5

Wang, D.I., Moeller, F.E. (1970) The division of labor and queen attendance behavior of Nosema-infected workers honey bees. J. Econ. Entomol. 63(5), 1539-1541

Winston, M.L. (1987) The biology of the honey bee. Harvard University Press, Cambridge
Woyciechowski, M. (2007) Risk of water collecting in honeybee (Apis mellifera) workers (Hymenoptera: Apidae). Sociobiology 50(3), 1059-1068

Woyciechowski, M., Kozlowski, J. (1998) Division of labour by division of risk according to worker life expectancy in the honey bee (Apis mellifera L.). Apidologie 29(1-2), 191-205

Woyciechowski, M., Moroń, D. (2009) Life expectancy and onset of foraging in the honeybee (Apis mellifera). Insectes Soc. 56(2), 193-201 